\title{
Prognostic and Predictive Epigenetic Biomarkers in Oncology
}

\author{
Katarzyna Kamińska ${ }^{1,2} \cdot$ Ewelina Nalejska ${ }^{1,2} \cdot$ Marta Kubiak $^{1,2} \cdot$ Joanna Wojtysiak $^{1,2} \cdot$ Łukasz Żołna $^{2}$. \\ Janusz Kowalewski ${ }^{2} \cdot$ Marzena Anna Lewandowska ${ }^{1,2}$
}

Published online: 6 December 2018

(c) The Author(s) 2018

\begin{abstract}
Epigenetic patterns, such as DNA methylation, histone modifications, and non-coding RNAs, can be both driver factors and characteristic features of certain malignancies. Aberrant DNA methylation can lead to silencing of crucial tumor suppressor genes or upregulation of oncogene expression. Histone modifications and chromatin spatial organization, which affect transcription, regulation of gene expression, DNA repair, and replication, have been associated with multiple tumors. Certain microRNAs (miRNAs), mainly those that silence tumor suppressor genes and occur in a greater number of copies, have also been shown to promote oncogenesis. Multiple patterns of these epigenetic factors occur specifically in certain malignancies, which allows their potential use as biomarkers. This review presents examples of tests for each group of epigenetic factors that are currently available or in development for use in early cancer detection, prediction, prognosis, and response to treatment. The availability of blood-based biomarkers is noted, as they allow sampling invasiveness to be reduced and the sampling procedure to be simplified. The article stresses the role of epigenetics as a crucial element of future cancer diagnostics and therapy.
\end{abstract}

\section{Key Points}

There is a broad spectrum of epigenetic biomarkers in oncology, but those related to methylation and microRNA (miRNA) copy number variation or changed expression seem to be the most promising.

There are a few diagnostics assays that provide prognostic and predictive information.

Epigenetic alterations have been identified in many solid tumors in formalin-fixed paraffin-embedded material; however, it seems that miRNAs and circulating tumor DNA are the most promising biological material to work with in personalized oncology.

Marzena Anna Lewandowska

lewandowskam@co.bydgoszcz.pl

1 Molecular Oncology and Genetics Department, Innovative Medical Forum, The F. Lukaszczyk Oncology Center, Bydgoszcz, Poland

2 Department of Thoracic Surgery and Tumors, L. Rydygier Collegium Medicum, Nicolaus Copernicus University, Bydgoszcz, Poland

\section{Introduction}

Genetic information is provided by the order of nucleotides arranged in DNA, but it is the pattern of epigenetic factors that dictates how this information should be expressed. Epigenetics answer the question of how the same genotype can be translated into different phenotypes [1]. Methylation of DNA, heritable modifications of chromatin (histone and nucleosome modifications), and regulation by non-coding RNAs are essential for normal development and maintenance of tissue-specific gene expression patterns in mammals [2, 3].

Epimutation is defined as a heritable abnormal transcriptional repression of gene activity that is not associated with a DNA sequence. Epimutation generally occurs in somatic cells and manifests as tumor progression but may also arise in the germline. Several diseases have been linked to epigenetic alterations. Epigenetic mutations and secondary genetic mutations in both cis and trans, including copy number variation (CNV), chromosomal rearrangements, and uniparental disomy [4], lead to eight classic imprinting disorders: (1) Angelman syndrome; (2) Prader-Willi syndrome [5]; (3) Beckwit-Wiedemann syndrome; (4) Silver-Russell syndrome; (5) Temple syndrome; (6) Wang syndrome [4]; (7) transient neonatal type 1 diabetes mellitus [6]; and (8) 
pseudohypoparathyroidism type 1 . Cancers associated with changes in the epigenetic landscape include Lynch syndrome (hereditary non-polyposis colorectal cancer [HNPCC]) (Table 1), chronic lymphocytic leukemia (CLL), breast cancer, and ovarian cancer. Many tumor suppressor genes (i.e., RBI, VHL, $M L H 1, A P C$, and $B R C A 1$ ) are involved in epigenetic abnormalities [3].

DNA methylation, histone modifications, and non-coding RNAs are present ubiquitously in all types of human malignancies and can appear at early stages of cancer, and therefore constitute particularly attractive markers with a wide range of applications in diagnostics [7].

The first epigenetic data were available in ENCODE (Encyclopedia of DNA Elements) for different cell lines. The first map of epigenetic changes in cancer tissue was included in The Cancer Genome Atlas (TCGA). Finally, the map of human epigenome has been developed under the Human Epigenome Project (HEP). Over the years, ENCODE has become a large database including information about the epigenome of 212 cell cultures, as well as that of many types of human cancer tissues. The HEP has expanded and united many international members, creating the International Human Epigenome Consortium (IHEC) [8]. Thus, we have gained a better understanding of the role of epigenetic changes in normal development, aging, imprinting disorders, and abnormal gene control in cancer, as well as the role of the environment in shaping phenotype in humans [9].

\section{Aberrant DNA Methylation in Cancer}

Aberrant DNA methylation is the main studied epigenetic alteration in cancer [10]. Aberrant hypermethylation of promoters in eukaryotic cells can lead to silencing of important genes, such as tumor suppressor genes, and ultimately result in the development of disease. Cancer development can also be affected by the opposite process. Hypomethylation of genes, e.g., oncogenes, which are normally methylated, can upregulate their expression [11]. Interestingly, DNA hypomethylation was the first reported DNA methylation abnormality in human cancer [12]. However, despite the initial evidence provided in 1983 and by later work, studies of the molecular mechanisms leading to cancer have not focused on epigenetics [12, 13]. Instead, the emphasis was put on DNA mutations and loss of heterozygosity (LOH) [11]. In 1999, Toyota et al. [14] proposed the CpG Island Methylator Phenotype (CIMP) as another pathway of tumorigenesis. They used CIMP to describe the clinical and pathological features of colorectal cancer (CRC) for the first time. This pioneering study consisted of methylation profiling of the CDKN2A (p16), MINT1, MINT2, MINT12, MINT17, MINT25, MINT27, MINT31, MLH1, and THBS1 genes in tumor tissue [15]. Almost 20 years after the publication by Toyota et al. [14], we have now developed methylation in vitro diagnostic (IVD) assays for blood and tissue [13]. Moreover, they have been successfully introduced in the clinical setting for cancer screening, prognosis, and prediction [15].

Table 1 Methylation: prognostic and predictive biomarkers with diagnostic utility

\begin{tabular}{|c|c|c|c|c|c|}
\hline Methylation & Prognostic & Predictive & $\begin{array}{l}\text { Invasive/non-inva- } \\
\text { sive diagnostics }\end{array}$ & $\begin{array}{l}\text { Biological } \\
\text { material }\end{array}$ & Target cancer \\
\hline $\begin{array}{l}M L H 1 \\
\text { Hypomethylation }\end{array}$ & + & - & Invasive & FFPE & Colorectal cancer $[16,17]$ \\
\hline $\begin{array}{l}M G M T \\
\text { Hypermethylation }\end{array}$ & + & + & Invasive & FFPE & Glioblastoma $[24,25]$ \\
\hline $\begin{array}{l}I D H 1 \text { p.R132H mutation and } M G M T \text { hyper- } \\
\text { methylation }\end{array}$ & + & - & Invasive & FFPE & Glioblastoma [30] \\
\hline$R B 1$ hypermethylation & + & - & Invasive & FFPE & Retinoblastoma $[33,34]$ \\
\hline GSTP1, RASSF1, APC methylation status & + & - & Invasive & FFPE & Prostate cancer $[35,36]$ \\
\hline SEPT9 & + & - & Non-invasive & Blood & $\begin{array}{l}\text { Colorectal cancer }[39,40] \\
\text { Lung cancer }[41]\end{array}$ \\
\hline$M G M T-S T P 27$ & - & + & Invasive & FFPE & $\begin{array}{l}\text { Oligodendrogliomas and } \\
\text { oligoastrocytomas [124] }\end{array}$ \\
\hline ESRl & - & + & Non-invasive & Blood & Breast cancer [125] \\
\hline ZNF331 & + & - & Invasive & FFPE & Colorectal cancer [126] \\
\hline SALL1 & - & + & Invasive & FFPE & Head and neck cancer [127] \\
\hline
\end{tabular}

FFPE formalin-fixed paraffin-embedded cancer tissue 


\subsection{DNA Methylation Biomarkers in Tissue}

One of the genes included in the first methylation profiling in 1999 was MLH1, a DNA mismatch repair (MMR) gene (Table 1). Epigenetic silencing of the $M L H I$ gene via hypermethylation of its promoter results in microsatellite instability (MSI). It has been found that $13 \%$ of sporadic CRCs show MLH1 hypermethylation, and a BRAF c.1799T>A, p.Val600Glu mutation has often also been identified in tumor DNA [16, 17]. MSI and loss of MLS1 also occurs in Lynch syndrome (the most common cause of hereditary CRC) [18], but it is caused by mutations in one of the DNA MMR genes. In order to fully diagnose Lynch syndrome, genetic analysis of constitutional mutations in the MMR genes is performed. Differentiation of non-heritable CRC and Lynch syndrome includes a two-level screening test. The first tier includes analysis of expression of MMR genes and MSI testing. In the case of loss of MMR expression and a positive result for MSI, constitutional mutations in MLH1, MSH2, MSH6, $P M S 2$, or EPCAM are analyzed. Alternatively, determination of the MLH1 methylation level and the BRAF V600E mutation is conducted. Constitutional $M L H 1$ epimutations testing is recommended to confirm Lynch syndrome [19]. Methylation analysis of $\mathrm{MLHI}$ can improve the selection of patients for Lynch syndrome genetic testing and thus reduce the cost of detecting a mutation by almost half [20]. MLHI methylation can be assessed by methylation-specific multiplex ligation-dependent probe amplification (MS-MLPA) $[21,22]$ and some laboratories use pyrosequencing [23].

Clinical trials have provided evidence that $\mathrm{O}^{6}$-methylguanine $\left(\mathrm{O}^{6}\right.$-meG)-DNA methyltransferase $(M G M T)$ is useful as a prognostic and predictive marker in glioblastoma (Table 1) [24, 25]. MGMT is a DNA repair gene participating in the removal of mutagenic and cytotoxic alkyl groups from $\mathrm{O}^{6}$-meG [28]. DNA alkylation leads to the formation of mutations, and therefore $M G M T$ protect cells against damage [26, 27]. Temozolomide causes alkyl DNA damage and thus leads to cell death. Its cytotoxic effect is more potent against the rapidly dividing cancer cells than against normal cells, as the DNA repair mechanisms in cancer cells are impaired [25, 28]. Therefore, cells with MGMT silenced by hypermethylation show a better response to temozolomide therapy [25]. It has been found that in glioma and CRC, methylation of MGMT occurs in $40 \%$ of tumors, while in non-small cell lung carcinomas (NSCLCs), lymphomas, and head and neck carcinomas, methylation of MGMT occurs in $25 \%$ of tumors [27]. Diagnostic recommendations for glioma include analysis of MGMT methylation, which is the key point in the therapeutic algorithm and provides predictive information about the response to temozolomide [29]. Furthermore, the MGMT methylation status in combination with $I D H 1$ mutations plays the role of a prognostic biomarker. Glioma patients with the IDHI p.R132H mutation and hypermethylated $M G M T$ have a better prognosis (Table 1) [30].

There are a number of commercial tests available to evaluate the MGMT methylation level by (1) methylationspecific polymerase chain reaction (PCR): PredictMDx Glioblastoma (MDx Health); (2) real-time PCR: MGMT Methylation Detection Kit (EntroGen); (3) MS-MLPA: SALSA MS-MLPA probe mix ME011 MMR genes (MRC-Holland); and (4) pyrosequencing technology: PyroMark MGMT Kit (Qiagen).

The $R B 1$ gene is primarily associated with retinoblastoma caused by the loss of the RBI function (Table 1). The lack of expression of this gene in retinoblastoma, as well as in other tumors, including bladder carcinomas and malignant neuroendocrine lung carcinomas, is associated with an $\mathrm{LOH}$ or RB1 mutations. Nevertheless, in some cases, the silencing of $R B 1$ expression is caused by its methylation $[31,32]$. It has been reported that for full molecular diagnostics of retinoblastoma, it is necessary to evaluate $R B 1$ methylation beyond the $\mathrm{LOH}$ and mutations. Ohtani-Fujita et al. [33] suggested that hypermethylation in the $R B 1$ gene is always acquired and causes approximately $9 \%$ of sporadic unilateral tumors [33]. Currently, there are tests available on the market based on the MS-MLPA methodology for the evaluation of the methylation level of the $R B 1$ promoter [34].

Tumor suppressor genes GSTP1, RASSF1, and APC are commonly methylated in prostate tumors and, therefore, are considered as cancer biomarkers (Table 1). A set of these genes has been used in a commercially available assayConfirmMDx ${ }^{\circledR}$ (MDxHealth). This test allows a better stratification of patients with a negative prostate biopsy result. It takes advantage of the epigenetic field effect, based on the principle that normal cells surrounding the foci of cancer can contain DNA methylation changes. Two independent studies, MATLOC (Methylation Analysis to Locate Occult Cancer) and DOCUMENT (Detection of Cancer Using Methylated Events in Negative Tissue), confirmed the predictive value of ConfirmMDx ${ }^{\circledR}$ and showed a sensitivity of $68 \%$, a specificity of $64 \%$, and a negative predictive value of $90 \%$ $[35,36]$. Moreover, it was found that use of the methylationbased biomarkers GSTP1, RASSF1, and APC resulted in a reduction of the number of unnecessary repeated biopsies by up to $64 \%$ [35].

\subsection{DNA Methylation Biomarkers in Biofluids}

Measurement of DNA methylation can be performed in various types of biological material—not only solid tissues, but also plasma, serum, sputum, urine, and cerebrospinal fluid (CSF). One of the examples of a plasma epigenetic biomarker for CRC screening is circulating methylated SEPT9 DNA (Table 1). SEPT9 regulates cell growth and prevents uncontrolled cell division and, therefore, it is considered to 
be a tumor suppressor [37]. It has been demonstrated that methylation of SEPT9 is associated with the pathogenesis of CRC, and a decrease in its expression is correlated with progression of neoplastic disease [38]. The first commercial diagnostic test based on the SEPT9 biomarker was developed by Epigenomics AG 10 years ago. It involves evaluation of the SEPT9 promoter methylation in plasma using real-time PCR [39]. Currently, two generations of these CE-marked IVD assays called Epi proColon ${ }^{\circledR}$ are available [39]. Other commercially available SEPT9 methylation tests for CRC diagnostics are ColoVantage ${ }^{\circledR}$ (Quest Diagnostics) and RealTime mS9 (Abbott) [40]. Apart from CRC, the usefulness of SEPT9 methylation has been evaluated in the early diagnostics of others cancers, including lung cancer [41]. However, there are more specific tests for lung cancer diagnostics, such as Epi proLung ${ }^{\circledR}$ (Epigenomics AG), in which methylation of SHOX2 and PTGER4 is evaluated using real-time PCR $[15,42]$. SHOX2 hypermethylation has been noticed in the bronchial aspirates [43], pleural effusions [44], and blood plasma of patients with lung cancer [15]. DNA methylation analysis of SHOX2 combined with PTGER4 in blood plasma allows detection of lung cancer and differentiation of non-malignant diseases [15]. Additionally, prognostic application of an assay based on SHOX2 methylation has been demonstrated [45]. The advantage of $S H O X 2$ as a methylation biomarker is its high specificity ( $>95 \%$ in bronchial aspirates) [43, 45].

In the case of CRC, in addition to the previously mentioned biomarkers, it is also possible to use a stool-based methylated biomarker test, i.e., the Cologuard ${ }^{\circledR}$ kit (Exact Sciences) [40, 46]. This PCR-based assay is used to assess the level of vimentin gene (VIM) methylation and DNA integrity for the early detection of CRC. The sensitivity and specificity of the Cologuard ${ }^{\circledR}$ assay are $83 \%$ and $82 \%$, respectively, and the specificity is almost at the same level in patients with CRC at stages I-III [47, 48].

\section{Histone Modification in Cancer}

Chromatin can generally be distinguished into heterochromatin, which is highly condensed and contains inactive genes, and euchromatin, which is more relaxed and contains actively transcribed genes. Covalent modification of the nucleosome components-histones-alters the organization and function of chromatin, which affects gene regulation and expression [49]. Histone modification plays an important role in the determination of the role of chromatin, which can be divided into six broad functions: promoter, enhancer, insulator, transcribed, repressed, and inactive chromatin [50]. Modification of histone structure includes phosphorylation, acetylation, methylation (mainly of lysine and arginine residues), ubiquitylation, glycosylation, SUMOylation,
ADP (adenosine diphosphate)-ribosylation, and carbonylation [49, 51]. Histone acetylation and methylation are often associated with a more relaxed chromatin conformation and are the main markers of active chromatin. On the other hand, histone deacetylation and phosphorylation are often associated with chromatin condensation and are markers of inactive chromatin [49].

Over the last 15 years, global histone modifications have been analyzed along with single acetylation and methylation of lysine and arginine residues in coding regions and non-promoter sequences. Importantly, global histone H3 and $\mathrm{H} 4$ modification patterns are potential markers of tumor recurrence and disease-free survival. NSCLC patients with global histone acetylation have shown a better prognosis in survival analysis than patients with globally methylated or non-modified histones, which were associated with poor prognosis [52]. The profiling of histone modifications allows patients to be classified into two subtypes, with distinct risks of tumor recurrence in patients with low-grade prostate cancer [53] and has also identified bladder cancer patients at risk of early cancer recurrence [54]. Since global profiling is more costly, single modifications are often evaluated as possible prognostic tools. For example, Fraga et al. [55] found that a global loss of $\mathrm{H} 4$ histone Lys16 monoacetylation and Lys20 trimethylation is associated with hypomethylation of DNA and is generally characteristic of human tumor cells. In breast cancer, a reduced status of H4Lys 16 acetylation and H4Lys 20 methylation is correlated with a worse prognosis [56]. However, the role of H4Lys 16 acetylation and H4Lys20 methylation in cancer pathogenesis requires further investigation.

Not only covalent modifications but also various isoforms of histone proteins present in the nucleosome can increase the predisposition to cancer. For example, overexpression of an H2A histone isoform, H2A.Z, has been observed in undifferentiated cancers and genitourinary cancers (prostate and bladder cancers). Furthermore, H2A.Z can play a role in endocrine resistance in breast cancer patients. It seems that H2A.Z can be useful as a tumor progression biomarker because of the correlation between the levels of H2A.Z and short overall patient survival [57].

Analysis of histones, as well as of their covalent modifications, have also been identified in blood derived from cancer patients. Circulating histones reflect changes in tumor cells, and therefore are promising non-invasive biomarkers originating from blood (Table 2). The presence of histones in blood is a result of tumor cell death (apoptosis and necrosis) or active release from living cells. Increasing the level of circulating nucleosomes/histones has recently been identified in the blood of patients in a wide range of cancers, e.g., breast, colorectal, and prostate cancers [58, 59]. However, a comparison of the levels of circulating histones in cancer patients to results obtained in patients with numerous benign 
Table 2 Histone modifications: prognostic and predictive biomarkers with diagnostic utility

\begin{tabular}{|c|c|c|c|c|c|}
\hline Histone modifications & Prognostic & Predictive & $\begin{array}{l}\text { Invasive/non-invasive } \\
\text { diagnostics }\end{array}$ & $\begin{array}{l}\text { Biological } \\
\text { material }\end{array}$ & Target cancer \\
\hline H3Cit & + & - & Non-invasive & Blood & Advanced cancers $[66]$ \\
\hline cf-nucleosome epitope combination & + & - & Non-invasive & Blood & Colorectal cancer [128] \\
\hline $\mathrm{H} 3 \mathrm{~K} 4 \mathrm{me} 3$ and $\mathrm{Wdr} 82$ expression & + & - & Non-invasive & Blood & Colorectal cancer [129] \\
\hline
\end{tabular}

FFPE formalin-fixed paraffin-embedded cancer tissue, H3Cit citrullinated histone 3

diseases has shown that the difference is not statistically significant, which reduces their clinical usefulness for detecting cancer [60]. Moreover, it has been found that the level of circulating nucleosomes can predict tumor responses to chemotherapeutic agents in various cancer types [61]. Increased levels of circulating nucleosomes have been associated with a worse response to chemotherapy in patients with advanced lung cancer [62], as well as to selective internal radiation therapy (SIRT) in metastasizing CRC [63].

Regarding post-translational histone modifications, the levels of H3K9me3 and H4K20me3 have been downregulated in the blood of CRC patients in comparison with cancer-free individuals $[64,65]$. In addition, a combination of H4K20me3 with H3K27me3 has shown an area under the curve (AUC) of 0.769 and a sensitivity of $49.2 \%$ at a $90 \%$ specificity for CRC patients [65]. Citrullinated histone 3 (H3Cit) has also recently been proposed as a prognostic biomarker in advanced cancers (Table 2). Thålin et al. [66] demonstrated a statistically significant correlation between the upregulation of circulating $\mathrm{H} 3 \mathrm{Cit}$ histone levels and short-term mortality.

\section{Mutations Affecting the SWitch/Sucrose Non-Fermentable (SWI/SNF) Chromatin Remodeling Complex}

Not only epigenetic modifications of chromatin, such as histone modifications, but also the spatial organization of chromatin plays a critical role in the regulation of all principal biological processes, such as transcription, regulation of gene expression, and DNA repair and replication.

The SWitch/Sucrose Non-Fermentable (SWI/SNF) chromatin remodeling complex is known to be mutated in up to $20 \%$ of human malignancies [49], including ovarian clearcell carcinoma, clear-cell renal cell carcinoma, hepatocellular carcinoma, gastric cancer, melanoma, and pancreatic cancer [67].

One of the SWI/SNF family members is the SMARCBI gene (hSNF5/INI1), which has been identified as a tumor suppressor gene [68]. Germline loss of function mutations in SMARCBI predispose to schwannomatosis and malignant rhabdoid tumor [69]. Biallelic inactivation has been observed in nearly all cases of childhood rhabdoid sarcoma (somatic alteration of SMARCB1 locus that encompasses a complete loss of one allele with nonsense mutations or silencing by methylation in the other allele) $[68,70]$. Identification of aberration of the SMARCB1 gene is generally more focused on genetic (point mutations, deletion, and amplifications) than epigenetic (methylation) changes. A broad range of diagnostic methods have been implemented to evaluate this marker in familial screening and rhabdoid tumor monitoring: PCR with bidirectional sequencing and microarray-based comparative genomic hybridization encompassing SMARCB1 [69], as well as MLPA assays together with fluorescence in situ hybridization (FISH) and single nucleotide polymorphism (SNP) array analysis (to identify the second inactivating event in rhabdoid tumors without homozygous SMARCB1 deletions) [71]. Finally, high-throughput technologies have been implemented: whole-genome (WGS) and whole-exome (WES) sequencing analysis, gene expression analysis using RNA sequencing and Illumina gene expression array, and, last but not least, epigenomic analysis using Illumina 450K DNA Methylation Array, Assay for Transposase-Accessible Chromatin using sequencing (ATAC-seq), and H3K27ac chromatin immunoprecipitation (ChIP) sequencing [71].

Another component of SWI/SNF chromatin remodeling is $A R I D 1 A$, in which frequent aberrations have been shown to be associated with different cancer types (Table 3), such as uterine carcinomas [72], pancreatic ductal adenocarcinomas [73], breast cancers [74], lung cancer [75], hepatocellular carcinomas [76], and gastric cancers [77]. Moreover, intragenic deletions of ARIDI (ARIDIA and ARIDIB) (Table 3) in neuroblastoma tumors [78] and breast cancer [79] correlate with a more aggressive phenotype and poor prognosis for patients. These studies suggest that ARIDI may be a valuable prognostic factor in a broad range of tumors, e.g., invasive breast cancer [80], gastric cancer [81], and ovarian cancer [82].

\section{Chromatin Conformation in Cancer}

Spatial organization of chromatin plays an important role in many malignant tumors, and chromosomal conformation changes inside the nucleus can be detected effectively using a broad spectrum of chromosome conformation capture 
Table 3 Chromatin conformation: prognostic and predictive biomarkers with diagnostic utility

\begin{tabular}{llllll}
\hline Chromatin conformation & Prognostic & Predictive & $\begin{array}{l}\text { Invasive/non-inva- } \\
\text { sive diagnostics }\end{array}$ & Biological material & Target cancer \\
\hline ARID1 (ARIDIA and ARIDB) & + & - & Non-invasive & Blood & Neuroblastoma tumors [78] \\
Methylation status of CTCF locus & + & - & Invasive & FFPE & Colorectal cancer [88] \\
SMARCA4/BRG1 & - & + & Invasive & Frozen tissue & Non-small cell lung cancer [130] \\
\hline
\end{tabular}

FFPE formalin-fixed paraffin-embedded cancer tissue

(3C)-based methods [83]. CTCF (CCCTC-binding factor) is a transcription factor that plays a crucial role in the formation of the three-dimensional chromatin architecture and epigenetic homeostasis and is present in over $86 \%$ of loops [84]. Disruption of the genomic neighborhood through abnormal CTCF binding to the imprinting control region can result in Beckwith-Wiedemann or Silver-Russell syndromes [85], and can be involved in various cancers (Table 3) [86].

Aberrations of $C T C F$ bindings depend on many mechanisms, including DNA methylation at the imprinting control region observed in testicular germ-cell tumors (TGCTs), CRC, bladder cancer, and ovarian cancer [87]. Liu et al. [88] indicated a set of five biomarkers (CTCF_13 [chr10: 15761963-15762083], CTCF_33 [chr13: 6156436961564467], CTCF_55 [chr17: 27940559-27940669], CTCF_94 [chr4: 165304966-165305120], and CTCF_113 [chr8: 69243102-69243188]) based on the methylation status of $C T C F$ binding sites that were considered as a diagnostic marker panel in CRC (Table 3) [88]. This panel achieves a sensitivity of $91.67 \%$ for adenomas, $97.44 \%$ for stage I CRC, $94.06 \%$ for stage II CRC, $93.62 \%$ for stage III CRC, and $93.54 \%$ for total colorectal tumors with a specificity of $94.05 \%$. As the $C T C F$ gene plays a critical role in gene silencing, in addition to abnormal $C T C F$ binding, loss of this gene is a known genetic event in an invasive and in situ carcinoma. Deletion of the 16q22.1 region in which the CTCF gene is located has been proposed as a novel biomarker for lobular carcinoma in situ (LCIS) [89].

\section{Aberrant MicroRNA (miRNA) in Cancer}

The microRNA (miRNA)-messenger RNA (mRNA) interactions are the second, after methylation, intensively studied epigenetic mechanism of gene regulation. miRNAs (miRs) were discovered in 1993 by Lee et al. [90] in Caenorhabditis elegans. They are small, non-coding RNA molecules of 18-25 nucleotides, which play a key role in the regulation of gene expression at the post-transcriptional level. miRNAs function by binding to the target mRNA molecule, thus inhibiting translation. It is estimated that up to $60 \%$ of genes encoding proteins can be controlled by miRNA.
The first evidence that miRNAs may be involved in the pathogenesis of human cancers was found in 2002 in a study of CLL [91]. This study showed that the deletion of $m i R-15 a$ and miR-16-1 genes located on chromosome 13q14 is associated with the development of CLL [91]. Moreover, it has been found that downregulation of these two miRNAs correlates with Bcl2 (antiapoptotic B cell lymphoma 2 protein) overexpression [92]. Bcl2 is involved in inhibiting cell death. Malignant B cells are immortalized due to the absence of miR15-a and miR16-1 that are able to repress Bcl2 at the post-transcriptional level [92]. Deletions of $m i R 15$ and miR16 located in cluster $13 \mathrm{q} 14.3$ were found in $\sim 65 \%$ of patients with CLL [92]. The simplest and most common diagnostic method for the detection of chromosomal rearrangements or deletion in locus 13q14.3 is to use FISH and evaluate the status of chromosomal changes in peripheral blood [93].

Dysregulation of miRNA expression significantly affects the regulation of many genes involved in cancer development. Overexpression of miRNA involved in the negative regulation of the suppressor gene can lead to the silencing of this suppressor. On the other hand, deletion of the chromosomal loci encoding the miRNA that silences the oncogene results in overexpression of this oncogene. Therefore, miRNAs themselves can act as suppressors, as well as oncogenes (oncomiRs). It is also important to remember that one miRNA molecule can regulate many genes, but also one mRNA can be targeted by several miRNAs.

Due to the changes in miRNA function and expression in cancer development, miRNAs can act as biomarkers and can be evaluated in both tumor tissue and blood derived from cancer patients.

\section{1 miRNA as a Cancer Biomarker in Solid Tissues}

Both fresh tissue and formalin-fixed paraffin-embedded (FFPE) tissue can be used for miRNA evaluation. It is wellknown that miRNA expression profiling or single miRNA evaluation performed on FFPE tissue corresponds well to fresh frozen (FF) tissue evaluation, as miRNA molecules are more resistant to formalin than mRNA [94]. When looking for miRNA biomarkers, it should be taken into account that changes in their expression can result from CNV. Therefore, 
miRNA analysis can be based on both expression and/or CNV evaluation.

One of the potential prognostic biomarkers in NSCLC is the set of four miRNAs (miR-30d, miR-21, miR-17, and $m i R-155)$ and two miRNA biogenesis genes (DICERl and DROSHA) (Table 4) [95]. In particular, miR-30d has been found to act as an oncomiR in cancer [96] and an increased copy number of $m i R$ - $30 \mathrm{~d}$ in cancer tissue (gains or amplifications vs. others) is correlated with significantly reduced survival [95] (Table 4). In contrast, it seems that miR-200b acts as a tumor suppressor: deletion or homozygous deletion of $m i R-200 b$ correlates with decreased survival of patients [95]. Finally, it has been found that an increased expression of DROSHA significantly correlates with a decreased survival, and DICERI amplification results in overexpression in cancer tissue [95]. This study suggested that CNV can be an important regulation mechanism of miRNA expression in cancer and shows a potential oncogenic role for $D R O$ SHA [95]. As was indicated by the authors, CNV (especially amplification, deletion, etc.) seems to be a very promising biomarker as DNA is more stable than RNA and is required in lower amounts to start a series. Finally, MLPA seems to be a cost effective and reliable method for copy number analysis [93].

Another interesting prognostic and predictive biomarker in metastatic CRC is miR-31-3p (Table 4) [97]. The expression level of this miRNA in FF or FFPE samples has been associated with progression-free survival during anti-epidermal growth factor receptor (EGFR) antibody therapy in $K R A S$ wild-type patients [97]. Following these data, a novel assay (MIRPREDX 31-3p) was launched in 2017 to measure the miR-31-3p expression in CRC. This test predicts which first-line chemotherapy is likely to be more beneficial to a patient with $R A S$ wild-type metastatic CRC: anti-EGFR or anti-vascular endothelial growth factor (VEGF) treatment. The test can also be used to establish when second or further lines of anti-EGFR therapy will be beneficial versus chemotherapy alone for patients with RAS wild-type metastatic CRC [136].

Another example of harnessing translational medicine biomarkers into the clinical setting is the miRview ${ }^{\circledR}$ lung assay (Rosetta Genomics Ltd.). This miRNA signature evaluates the expression of $h s a-m i R-106 a, h s a-m i R-125 a-5 p$, hsa-miR-129-3p, hsa-miR-205, hsa-miR-21, hsa-miR-29b, hsa-miR-375, and hsa-miR-7 in histopathology and cytology samples using real-time PCR (Table 4) [98]. Assessment of these miRNAs distinguishes squamous from non-squamous NSCLC (with $97 \%$ sensitivity and $91 \%$ specificity) and is a novel tool for differentiating primary lung cancer into four subgroups with an overall accuracy of $94 \%$ : squamous cell lung carcinoma, non-squamous cell lung carcinoma, carcinoid, and small-cell lung carcinoma [98].

Tissue miRNA profiles seem to be very valuable diagnostic biomarkers; however, one of their limitations is the invasiveness of the method used to obtain tissue samples for testing.

\section{2 miRNA as a Cancer Biomarker in Biofluids}

Tumor cells release miRNAs into body fluids, such as plasma, serum, urine, and saliva. Therefore, analysis of circulating miRNAs in samples of liquid biopsy provides promising biomarkers for non-invasive diagnostics in many human cancers, including colorectal, lung, breast, prostate,

Table 4 MicroRNA: prognostic and predictive biomarkers with diagnostic utility

\begin{tabular}{|c|c|c|c|c|c|}
\hline miRNA & Prognostic & Predictive & $\begin{array}{l}\text { Invasive/non-invasive diag- } \\
\text { nostics }\end{array}$ & Biological material & Target cancer \\
\hline$m i R-21$ & + & + & Invasive/non-invasive & FFPE/blood & $\begin{array}{l}\text { Multiple types of cancers } \\
\text { [104-108] }\end{array}$ \\
\hline$m i R-30 d, m i R-21$ & + & - & Invasive & FFPE & Non-small cell lung cancer [95] \\
\hline$m i R-31-3 p$ & + & + & Invasive & FFPE & Colorectal cancer [97] \\
\hline $\begin{array}{l}\text { miR-106a, miR125a-5p, miR- } \\
\text { 129-3p, miR-205, miR-21, } \\
\text { miR-29b, miR-375, miR-7 }\end{array}$ & + & - & Invasive & FFPE & Non-small cell lung cancer [98] \\
\hline$m i R-29 a, m i R-92 a$ & + & - & Non-invasive & Blood & Colorectal cancer [131] \\
\hline$m i R-506, m i R-4316$ & + & - & Non-invasive & Blood & Colorectal cancer [132] \\
\hline $\begin{array}{l}m i R-126, m i R-145, m i R-210, \\
\quad m i R-205-5 p\end{array}$ & + & - & Non-invasive & Blood & Non-small cell lung cancer [133] \\
\hline $\begin{array}{l}\text { miR-149-3p, miR-150-5p, miR- } \\
\quad 193 a-3 p\end{array}$ & + & - & Non-invasive & Blood & Melanoma [134] \\
\hline$m i R-200$ family, $m i R-17$ family & - & + & Non-invasive & Blood & Prostate cancer [135] \\
\hline$m i R-17, m i R-155$ & + & - & Invasive & FFPE & Non-small cell lung cancer [95] \\
\hline
\end{tabular}

FFPE formalin-fixed paraffin-embedded cancer tissue, miRNA microRNA 
gastric, pancreatic, esophageal, liver, thyroid, kidney, ovarian, endometrial, and cervical cancers, as well as melanoma and rhabdomyosarcoma [99]. However, although many potential cell-free circulating miRNA biomarkers have been identified in several types of cancer, there is no proportional reflection in the number of diagnostic tests developed.

There are many miRNAs dysregulated in cancers whose changes are reflected in blood. Among the well-known miRNAs with altered expression in tumors is the let-7 family: let-7a-1, 7a-2, 7a-3, 7b, 7c, 7d, 7e, 7f-1, 7f-2, 7g, 7i, miR-98, and $m i R-202$ [100]. The let-7 family are considered to be tumor suppressors, because selected members of this family are downregulated in melanoma, pancreatic cancer, prostate cancer, and sarcoma [101]. However, they can also be upregulated in lymphoma, mesothelioma, and breast cancer [101]. Circulating let-7 has been described as serum/plasma-based diagnostic tools in those cancers. However, those specific miRNAs that allow metastatic and non-metastatic patients to be distinguished, help to discriminate the different histological subtypes, or provide predictive information are the most diagnostically valuable.

It was found that miR-21 silences the expression of many tumor suppressors, so it functions as an oncogene ('oncomiR') (Table 4) [102]. This miRNA targets, for example, $P D C D 4$, which is associated with inhibition of neoplastic transformation, cancer promotion, progression, and invasion [101-105]. Among the other targets of $m i R$ 21 are BCL2, PTEN, RECK, RHOB, and TPM1 [106]. The diagnostic, predictive, and/or prognostic role of this miRNA has been described in hematological cancers, breast cancer, gastric cancer, ovarian cancer, pancreatic cancer, CRC, lung cancer, and liver cancer [104-108]. Abnormal expression of miR-21 has been demonstrated in many cancers, and it has been used in commercial tests not only as a single miRNA but also in small panels.

$m i R-21$, along with many other miRNAs, is included in the Lumira test, which is under development by Microlin Bio, Inc. Lumira ${ }^{\mathrm{TM}}$ is intended to help diagnose and determine the risk of developing lung cancer. Microlin Bio, Inc. is also working on the development of other tests: Omira ${ }^{\mathrm{TM}}$, employing $m i R-484$, for the screening and analysis of the chemosensitivity of ovarian cancer; Colomira ${ }^{\mathrm{TM}}$, employing a $m i R-17$ cluster for the diagnosis and prognosis of colon cancer, as well as determination of its sensitivity to therapies; and Promira ${ }^{\mathrm{TM}}$, employing $m i R-34 a$, for the diagnosis and prognosis of prostate cancer.

The expression of $m i R-21$ has also been evaluated in plasma derived from gastric cancer patients with a sensitivity of $66.5 \%$, a specificity of $83.1 \%$, and an AUC of 0.8 [109]. Interestingly, a combination of $m i R-21$ with $m i R$ $106 \mathrm{~b}$ has demonstrated a sensitivity of $69 \%$, a specificity of $69.4 \%$, and an AUC of 0.7 [110], while the combination of $m i R-21$ with $m i R-223$ and $m i R-218$ has shown a sensitivity of $84.29 \%$, a specificity of $92.86 \%$, and an AUC of 0.9531 [96]. In gastric cancer, measuring the expression level of different miRNAs, including hsa-miR-21-3p, was patented in 2014 [137], and a CE IVD test-MIRXES gastric cancer kit (MiRXES, ID3AL) - has been introduced into the market for the miRNA expression profile in blood.

\section{Influence of Epigenetics on Standard Therapeutic Options in Cancer}

The main way to prevent deaths from CRC and to improve the cure rate is regular screening. The US Preventive Services Task Force (USPSTF) has shown that approximately $60 \%$ of CRC deaths could be avoided with periodic screening, and the average 5-year survival rate could be increased from $46 \%$ to $73 \%$ [111]. According to the guidelines of the American Cancer Society, CRC screening in people at average risk should begin at the age of 45 years. Colonoscopy is one of the visual examinations of CRC and should be performed every 10 years. For people at increased risk, screening should start earlier and be performed more often [112]. Unfortunately, colonoscopy is associated with significant discomfort and thus patients tend to avoid it. Statistics show that less than $60 \%$ of eligible adults adhere to screening recommendations [113]. It is believed that more patient-friendly approaches, such as analysis of the SEPT9 methylation level in blood, might encourage people who did not follow the screening recommendations due to the fear of this invasive examination [111]. A meta-analysis performed by Nian et al. [113] based on 25 studies assessing the diagnostic utility of the SEPT9 assay showed that pooled sensitivity was 0.71 , specificity was 0.92 , and the AUC was 0.88 . Among the various methods and assays, Epipro Colon ${ }^{\circledR} 2.0$ with 2/3 algorithm was the most effective in CRC detection [113].

Methylation of MGMT occurs in 35-45\% of malignant gliomas (World Health Organization [WHO] grades III and IV) and in about $80 \%$ of WHO grade II gliomas. At present, radiotherapy with concomitant and adjuvant temozolomide chemotherapy is the standard treatment for glioblastoma. The presence of the methylated MGMT promoter has been seen to improve median overall survival (21.7 vs. 12.7 months) and progression-free survival compared with patients without methylation [114]. Thus, the MGMT methylation status is important when making clinical decisions in an older glioblastoma patient. In the elderly subpopulation, $M G M T$ promoter methylation is an important biomarker for personalized treatment strategies. It should be taken into account that chemoradiotherapy including temozolomide might be too toxic for the elderly. Overall survival in methylated patients was better when temozolomide treatment 
was used, whereas radiotherapy alone was more effective in unmethylated patients $[114,115]$.

Due to the high risk of a standard brain biopsy, the assessment of $M G M T$ methylation in a non-invasive liquid biopsy seems to be an attractive alternative. Unfortunately, the use of serum circulating tumor DNA (ctDNA) analysis for tumors of the nervous system is difficult due to the impermeability of the blood-brain barrier. Studies show that the sensitivity of detection of the $M G M T$ promoter methylation in blood serum, expressed as the percentage of positive serum samples among patients with $M G M T$ methylation detected in tissue samples, is low (37.3\%), but the use of CSF can increase the sensitivity of detection to $65.0 \%$. However, it seems that the overall sensitivity of liquid biopsy (including CSF) is significantly lower than that of tissue samples [116]. Therefore, detection of $M G M T$ promoter methylation in tissue is more reasonable for diagnostic purposes.

\section{Epigenetic Therapy: Clinical Trials}

Targeting enzymatic regulators responsible for epigenetic events holds promise for modulating the transcriptional regulation of genes involved in cancer [117]. Additionally, reversal of epigenetic changes represents a potential target for novel preventive and therapeutic strategies, as well as medication design [118]. Epigenetic therapy primarily involves DNA methylation inhibitors (DNMTi) and histone deacetylase inhibitors (HDACi) [119]. To date, five epidrugs have been approved by the US Food and Drug Administration (FDA) (two DNMTi and three HDACi) and are described as the first generation of epigenetic inhibitors in cancer treatment. At present, 21 clinical trials using epigenetic drugs as epigenetic cancer therapy are registered at ClinicalTrials.gov. Most of them involve lung cancer, cervical carcinoma, CRC, and pancreatic adenocarcinoma.

DNMTi entered clinical trials as classical anticancer agents more than 40 years ago. The role of DNMTi is to remove the hypermethylation of tumor suppressor genes [120]. DNMTi are classified into two categories: nucleoside and non-nucleoside inhibitors. The cytosine analogs, azacytidine (5-azacytidine) and decitabine (5-aza-2'deoxycytidine), belong to the first-generation epigenetic nucleoside inhibitors that intercalate with the DNA. These epidrugs are approved by the FDA and used in the treatment for myeloid leukemias [120]. In recent years second-generation nucleoside DNMTi have been developed and preclinical and clinical studies are ongoing for their use as therapy against advanced solid tumors and leukemias [121].

HDACi reduce oncogene transcription and angiogenesis, induce cancer cell cycle arrest, and modulate immune response [122]. The use of HDACi has been clinically validated in cancer treatment and four drugs have been approved by the FDA: vorinostat, romidepsin, panobinostat, and belinostat [120]. Belinostat has been approved as an epigenetic compound for the treatment of peripheral $\mathrm{T}$ cell lymphoma, vorinostat and romidepsin have been approved for the treatment of cutaneous manifestations in patients with cutaneous $\mathrm{T}$ cell lymphoma (CTCL), and panobinostat in combination with the proteasome inhibitor bortezomib has been approved for use in patients with multiple myeloma [120].

Epigenetic drugs have shown very modest antitumor efficacy, with some responses seen in a small percentage of cancer patients ( $3 \%$ of patients responded to epidrugs in a single therapy, $20 \%$ of patients responded to epidrugs in combination with other chemotherapies) [123]. Additionally, epidrugs used in cancer treatment will potentially have genome-wide effects, such as uncontrolled upregulation of unwanted genes, e.g., oncogenes [123]. Therefore, development of therapies targeting specific epigenetic defects in cancer can provide a novel approach to prevent such unwanted events.

Therapeutic strategies for cancer will exhibit the greatest effectiveness with treatment approaches based not on single therapies but on juxtaposition of mutational events and epigenetic alterations [120].

\section{Summary}

Epigenetic modifications of DNA and gene regulation by miRNA are the hope and promise of novel biomarkers for early cancer detection, prediction, prognosis, and response to treatment. The most commonly used epigenetic biomarkers were first investigated in solid tissues, but acquiring this material using invasive techniques limits the potential of early cancer detection and screening programs. The ideal sampling source is blood in which circulating free DNA and miRNAs can be measured using minimally invasive techniques, and one which can be used in all patients - those at both minimal and high risk [118]. Obviously, the phases of development of biomarkers, from quality control, analytical and clinical validation to the approved biomarker ready for clinical use, are expensive and time-consuming, but this work can be conducted through interdisciplinary collaboration between researchers, diagnosticians, and diagnostics companies.

Alteration of DNA methylation, histone modifications, and miRNAs often helps to better differentiate tumor subtypes and bring new prognostic information related to patient survival in relation to age, sex, etc. On the other hand, there are also a few epigenetic biomarkers that predict response to chemotherapeutic agents, the most common being MGMT promoter methylation, which predicts response to temozolomide. International epigenetic projects have allowed not only better characterization of novel biomarkers, but have also 
opened a new strategy in pharmacology. Reversal of epigenetic changes represents a potential target for novel preventive and therapeutic strategies, as well as medication design [118]. Epigenetic therapy primarily involves DNMTi and HDACi that have been clinically validated in cancer treatment [119]. Therapeutic strategies for cancer will exhibit the greatest efficiency with treatment approaches based not only on single therapies but on juxtaposition of mutational events and epigenetic alterations [120].

\section{Compliance with Ethical Standards}

Funding This study was supported by grants from the International Centre for Genetic Engineering and Biotechnology-POL 13-01 contract CRP 13/024.

Conflict of interest Katarzyna Kamińska, Ewelina Nalejska, Marta Kubiak, Joanna Wojtysiak, Łukasz Żołna, Janusz Kowalewski, and Marzena Anna Lewandowska have no conflicts of interest to declare.

Open Access This article is distributed under the terms of the Creative Commons Attribution-NonCommercial 4.0 International License (http://creativecommons.org/licenses/by-nc/4.0/), which permits any noncommercial use, distribution, and reproduction in any medium, provided you give appropriate credit to the original author(s) and the source, provide a link to the Creative Commons license, and indicate if changes were made.

\section{References}

1. Esteller M. The necessity of a human epigenome project. Carcinogenesis. 2006;27(6):1121-5.

2. Sharma S, Kelly TK, Jones PA. Epigenetics in cancer. Carcinogenesis. 2010;31(1):27-36.

3. Banno K, Kisu I, Yanokura M, Tsuji K, Masuda K, Ueki A, et al. Epimutation and cancer: a new carcinogenic mechanism of Lynch syndrome (Review). Int J Oncol. 2012;41(3):793-7.

4. Poole RL, Docherty LE, Al Sayegh A, Caliebe A, Turner C, Baple E, et al. Targeted methylation testing of a patient cohort broadens the epigenetic and clinical description of imprinting disorders. Am J Med Genet A. 2013;161A(9):2174-82.

5. Ehrhart F, Janssen KJM, Coort SL, Evelo CT, Curfs LMG. Prader-Willi syndrome and Angelman syndrome: visualisation of the molecular pathways for two chromosomal disorders. World J Biol Psychiatry. 2018;1:1-13.

6. Gardner RJ, Mackay DJ, Mungall AJ, Polychronakos C, Siebert $\mathrm{R}$, Shield JP, et al. An imprinted locus associated with transient neonatal diabetes mellitus. Hum Mol Genet. 2000;9(4):589-96.

7. Costa FF. Epigenomics in cancer management. Cancer Manag Res. 2010;27(2):255-65.

8. Bae J-B. Perspectives of international human epigenome consortium. Genom Inform. 2013;11(1):7-14.

9. Jones PA, Martienssen R. A blueprint for a human epigenome project: the AACR human epigenome workshop. Cancer Res. 2005;65(24):11241-6.

10. Baylin SB. DNA methylation and gene silencing in cancer. Nat Clin Pract Oncol. 2005;2(Suppl 1):S4-11.

11. Søes S, Daugaard IL, Sørensen BS, Carus A, Mattheisen M, Alsner J, et al. Hypomethylation and increased expression of the putative oncogene ELMO3 are associated with lung cancer development and metastases formation. Oncoscience. 2014;1(5):367-74.

12. Feinberg AP, Vogelstein B. Hypomethylation distinguishes genes of some human cancers from their normal counterparts. Nature. 1983;301(5895):89-92.

13. Curtin K, Slattery ML, Samowitz WS. CpG island methylation in colorectal cancer: past, present and future. Patholog Res Int 2011;12(2011):902674.

14. Toyota M, Ahuja N, Ohe-Toyota M, Herman JG, Baylin SB, Issa JP. CpG island methylator phenotype in colorectal cancer. Proc Natl Acad Sci USA. 1999;96(15):8681-6.

15. Weiss G, Schlegel A, Kottwitz D, König T, Tetzner R. Validation of the SHOX2/PTGER4 DNA methylation marker panel for plasma-based discrimination between patients with malignant and nonmalignant lung disease. J Thorac Oncol. 2017;12(1):77-84.

16. Weisenberger DJ, Siegmund KD, Campan M, Young J, Long TI, Faasse MA, et al. CpG island methylator phenotype underlies sporadic microsatellite instability and is tightly associated with BRAF mutation in colorectal cancer. Nat Genet. 2006;38(7):787-93.

17. Jass JR. Classification of colorectal cancer based on correlation of clinical, morphological and molecular features. Histopathology. 2007;50(1):113-30.

18. Rustgi AK. The genetics of hereditary colon cancer. Genes Dev. 2007;21(20):2525-38.

19. Giardiello FM, Allen JI, Axilbund JE, Boland CR, Burke CA, Burt RW, et al. Guidelines on genetic evaluation and management of Lynch syndrome: a consensus statement by the U.S. Multi-Society Task Force on Colorectal Cancer. Gastrointest Endosc. 2014;80(2):197-220.

20. Pérez-Carbonell L, Alenda C, Payá A, Castillejo A, Barberá VM, Guillén C, et al. Methylation analysis of MLH1 improves the selection of patients for genetic testing in Lynch syndrome. J Mol Diagn. 2010;12(4):498-504.

21. Castillejo A, Hernández-Illán E, Rodriguez-Soler M, Pérez-Carbonell L, Egoavil C, Barberá VM, et al. Prevalence of MLH1 constitutional epimutations as a cause of Lynch syndrome in unselected versus selected consecutive series of patients with colorectal cancer. J Med Genet. 2015;52(7):498-502.

22. Ozer O, Bilezikci B, Aktas S, Sahin FI. Methylation profile analysis of DNA repair genes in hepatocellular carcinoma with MS-MLPA. Diagn Mol Pathol. 2013;22(4):222-7.

23. Newton K, Jorgensen NM, Wallace AJ, Buchanan DD, Lalloo F, McMahon RF, et al. Tumour MLH1 promoter region methylation testing is an effective prescreen for Lynch Syndrome (HNPCC). J Med Genet. 2014;51(12):789-96.

24. Wick W, Platten M, Meisner C, Felsberg J, Tabatabai G, Simon $\mathrm{M}$, et al. Temozolomide chemotherapy alone versus radiotherapy alone for malignant astrocytoma in the elderly: the NOA-08 randomised, phase 3 trial. Lancet Oncol. 2012;13(7):707-15.

25. Cabrini G, Fabbri E, Lo Nigro C, Dechecchi MC, Gambari R. Regulation of expression of O6-methylguanine-DNA methyltransferase and the treatment of glioblastoma (Review). Int J Oncol. 2015;47(2):417-28.

26. Coulondre C, Miller JH. Genetic studies of the lac repressor. IV. Mutagenic specificity in the lacI gene of Escherichia coli. J Mol Biol. 1977;117(3):577-606.

27. Esteller M, Hamilton SR, Burger PC, Baylin SB, Herman JG. Inactivation of the DNA repair gene O6-methylguanineDNA methyltransferase by promoter hypermethylation is a common event in primary human neoplasia. Cancer Res. 1999;59(4):793-7.

28. Chakravarti A, Erkkinen MG, Nestler U, Stupp R, Mehta M, Aldape K, et al. Temozolomide-mediated radiation enhancement 
in glioblastoma: a report on underlying mechanisms. Clin Cancer Res. 2006;12(15):4738-46.

29. Weller M, Pfister SM, Wick W, Hegi ME, Reifenberger G, Stupp R. Molecular neuro-oncology in clinical practice: a new horizon. Lancet Oncol. 2013;14(9):e370-9.

30. Roszkowski K, Furtak J, Zurawski B, Szylberg T, Lewandowska MA. Potential role of methylation marker in glioma supporting clinical decisions. Int J Mol Sci. 2016;17(11):1876.

31. Greger V, Passarge E, Höpping W, Messmer E, Horsthemke B. Epigenetic changes may contribute to the formation and spontaneous regression of retinoblastoma. Hum Genet. 1989;83(2):155-8.

32. Simpson DJ, Hibberts NA, McNicol AM, Clayton RN, Farrell WE. Loss of $\mathrm{pRb}$ expression in pituitary adenomas is associated with methylation of the RB1 CpG island. Cancer Res. 2000;60(5):1211-6.

33. Ohtani-Fujita N, Dryja TP, Rapaport JM, Fujita T, Matsumura $\mathrm{S}$, Ozasa $\mathrm{K}$, et al. Hypermethylation in the retinoblastoma gene is associated with unilateral, sporadic retinoblastoma. Cancer Genet Cytogenet. 1997;98(1):43-9.

34. Livide G, Epistolato MC, Amenduni M, Disciglio V, Marozza A, Mencarelli MA, et al. Epigenetic and copy number variation analysis in retinoblastoma by MS-MLPA. Pathol Oncol Res. 2012;18(3):703-12.

35. Stewart GD, Van Neste L, Delvenne P, Delrée P, Delga A, McNeill SA, et al. Clinical utility of an epigenetic assay to detect occult prostate cancer in histopathologically negative biopsies: results of the MATLOC study. J Urol. 2013;189(3):1110-6.

36. Partin AW, Van Neste L, Klein EA, Marks LS, Gee JR, Troyer DA, et al. Clinical validation of an epigenetic assay to predict negative histopathological results in repeat prostate biopsies. J Urol. 2014;192(4):1081-7.

37. Burrows JF, Chanduloy S, McIlhatton MA, Nagar H, Yeates K, Donaghy P, et al. Altered expression of the septin gene, SEPT9, in ovarian neoplasia. J Pathol. 2003;201(4):581-8.

38. Tóth K, Galamb O, Spisák S, Wichmann B, Sipos F, Valcz $\mathrm{G}$, et al. The influence of methylated septin 9 gene on RNA and protein level in colorectal cancer. Pathol Oncol Res. 2011;17(3):503-9.

39. Wang Y, Chen P-M, Liu R-B. Advance in plasma SEPT9 gene methylation assay for colorectal cancer early detection. World $\mathbf{J}$ Gastrointest Oncol. 2018;10(1):15-22.

40. Mikeska T, Craig JM. DNA methylation biomarkers: cancer and beyond. Genes. 2014;5(3):821-64.

41. Powrózek T, Krawczyk P, Kucharczyk T, Milanowski J. Septin 9 promoter region methylation in free circulating DNA-potential role in noninvasive diagnosis of lung cancer: preliminary report. Med Oncol. 2014;31(4):917.

42. Nikolaidis G, Raji OY, Markopoulou S, Gosney JR, Bryan J, Warburton C, et al. DNA methylation biomarkers offer improved diagnostic efficiency in lung cancer. Cancer Res. 2012;72(22):5692-701.

43. Schmidt B, Liebenberg V, Dietrich D, Schlegel T, Kneip C, Seegebarth A, et al. SHOX2 DNA methylation is a biomarker for the diagnosis of lung cancer based on bronchial aspirates. BMC Cancer. 2010;3(10):600.

44. Ilse P, Biesterfeld S, Pomjanski N, Fink C, Schramm M. SHOX2 DNA methylation is a tumour marker in pleural effusions. Cancer Genomics Proteomics. 2013;10(5):217-23.

45. Dietrich D, Jung M, Puetzer S, Leisse A, Holmes EE, Meller S, et al. Diagnostic and prognostic value of SHOX2 and SEPT9 DNA methylation and cytology in benign, paramalignant and malignant pleural effusions. PloS One. 2013;8(12):e84225.

46. Li Y-W, Kong F-M, Zhou J-P, Dong M. Aberrant promoter methylation of the vimentin gene may contribute to colorectal carcinogenesis: a meta-analysis. Tumour Biol. 2014;35(7):6783-90.
47. Itzkowitz S, Brand R, Jandorf L, Durkee K, Millholland $\mathrm{J}$, Rabeneck L, et al. A simplified, noninvasive stool DNA test for colorectal cancer detection. Am J Gastroenterol. 2008;103(11):2862-70.

48. Lao VV, Grady WM. Epigenetics and colorectal cancer. Nat Rev Gastroenterol Hepatol. 2011;8(12):686-700.

49. Dawson MA, Kouzarides T. Cancer epigenetics: from mechanism to therapy. Cell. 2012;150(1):12-27.

50. Ernst J, Kheradpour P, Mikkelsen TS, Shoresh N, Ward LD, Epstein CB, et al. Mapping and analysis of chromatin state dynamics in nine human cell types. Nature. 2011;473(7345):43-9.

51. Kurdistani SK. Histone modifications as markers of cancer prognosis: a cellular view. Br J Cancer. 2007;97(1):1-5.

52. Song JS, Kim YS, Kim DK, Park SI, Jang SJ. Global histone modification pattern associated with recurrence and diseasefree survival in non-small cell lung cancer patients. Pathol Int. 2012;62(3):182-90.

53. Seligson DB, Horvath S, Shi T, Yu H, Tze S, Grunstein M, et al. Global histone modification patterns predict risk of prostate cancer recurrence. Nature. 2005;435(7046):1262-6.

54. Ellinger J, Schneider A-C, Bachmann A, Kristiansen G, Müller SC, Rogenhofer S. Evaluation of global histone acetylation levels in bladder cancer patients. Anticancer Res. 2016;36(8):3961-4.

55. Fraga MF, Ballestar E, Paz MF, Ropero S, Setien F, Ballestar ML, et al. Epigenetic differences arise during the lifetime of monozygotic twins. Proc Natl Acad Sci USA. 2005;102(30):10604-9.

56. Elsheikh SE, Green AR, Rakha EA, Powe DG, Ahmed RA, Collins HM, et al. Global histone modifications in breast cancer correlate with tumor phenotypes, prognostic factors, and patient outcome. Cancer Res. 2009;69(9):3802-9.

57. Monteiro FL, Baptista T, Amado F, Vitorino R, Jerónimo C, Helguero LA. Expression and functionality of histone H2A variants in cancer. Oncotarget. 2014;5(11):3428-43.

58. Yörüker EE, Holdenrieder S, Gezer U. Potential of circulating nucleosome-associated histone modifications in cancer. Transl Cancer Res. 2017;7(2):S185-91.

59. McAnena P, Brown JAL, Kerin MJ. Circulating nucleosomes and nucleosome modifications as biomarkers in cancer. Cancers (Basel). 2017;9(1):5.

60. Holdenrieder S, Stieber P, Bodenmüller H, Busch M, Fertig G, Fürst $\mathrm{H}$, et al. Nucleosomes in serum of patients with benign and malignant diseases. Int J Cancer. 2001;95(2):114-20.

61. Stoetzer OJ, Fersching DMI, Salat C, Steinkohl O, Gabka CJ, Hamann U, et al. Prediction of response to neoadjuvant chemotherapy in breast cancer patients by circulating apoptotic biomarkers nucleosomes, DNAse, cytokeratin-18 fragments and survivin. Cancer Lett. 2013;336(1):140-8.

62. Holdenrieder S, Stieber P, von Pawel J, Raith H, Nagel D, Feldmann K, et al. Circulating nucleosomes predict the response to chemotherapy in patients with advanced non-small cell lung cancer. Clin Cancer Res. 2004;10(18 Pt 1):5981-7.

63. Fahmueller YN, Nagel D, Hoffmann R-T, Tatsch K, Jakobs T, Stieber P, et al. Predictive and prognostic value of circulating nucleosomes and serum biomarkers in patients with metastasized colorectal cancer undergoing selective internal radiation therapy. BMC Cancer. 2012;4(12):5.

64. Gezer U, Holdenrieder S. Post-translational histone modifications in circulating nucleosomes as new biomarkers in colorectal cancer. Vivo. 2014;28(3):287-92.

65. Gezer U, Yörüker EE, Keskin M, Kulle CB, Dharuman Y, Holdenrieder S. Histone methylation marks on circulating nucleosomes as novel blood-based biomarker in colorectal cancer. Int J Mol Sci. 2015;16(12):29654-62.

66. Thålin $\mathrm{C}$, Lundström $\mathrm{S}$, Seignez $\mathrm{C}$, Daleskog $\mathrm{M}$, Lundström A, Henriksson P, et al. Citrullinated histone $\mathrm{H} 3$ as a novel 
prognostic blood marker in patients with advanced cancer. PloS One. 2018;13(1):e0191231.

67. Shain AH, Pollack JR. The spectrum of SWI/SNF mutations, ubiquitous in human cancers. PloS One. 2013;8(1):e55119.

68. Versteege I, Sévenet N, Lange J, Rousseau-Merck MF, Ambros $\mathrm{P}$, Handgretinger R, et al. Truncating mutations of hSNF5/INI1 in aggressive paediatric cancer. Nature. 1998;394(6689):203-6.

69. Swensen JJ, Keyser J, Coffin CM, Biegel JA, Viskochil DH, Williams MS. Familial occurrence of schwannomas and malignant rhabdoid tumour associated with a duplication in SMARCB1. J Med Genet. 2009;46(1):68-72.

70. Hargreaves DC, Crabtree GR. ATP-dependent chromatin remodeling: genetics, genomics and mechanisms. Cell Res. 2011;21(3):396-420.

71. Torchia J, Golbourn B, Feng S, Ho KC, Sin-Chan P, Vasiljevic $\mathrm{A}$, et al. Integrated (epi)-genomic analyses identify subgroupspecific therapeutic targets in CNS rhabdoid tumors. Cancer Cell. 2016;30(6):891-908.

72. Wiegand KC, Lee AF, Al-Agha OM, Chow C, Kalloger SE, Scott DW, et al. Loss of BAF250a (ARID1A) is frequent in high-grade endometrial carcinomas. J Pathol. 2011;224(3):328-33.

73. Zhang L, Lu Z, Zhao Q, Huang J, Shen H, Zhang Z. Enhanced chemotherapy efficacy by sequential delivery of siRNA and anticancer drugs using PEI-grafted graphene oxide. Small. 2011;7(4):460-4.

74. Cornen S, Adélaide J, Bertucci F, Finetti P, Guille A, Birnbaum $\mathrm{D}$, et al. Mutations and deletions of ARID1A in breast tumors. Oncogene. 2012;16(31):4255-6.

75. Huang J, Zhao Y-L, Li Y, Fletcher JA, Xiao S. Genomic and functional evidence for an ARID1A tumor suppressor role. Genes Chromosomes Cancer. 2007;46(8):745-50.

76. Guichard C, Amaddeo G, Imbeaud S, Ladeiro Y, Pelletier L, Maad IB, et al. Integrated analysis of somatic mutations and focal copy-number changes identifies key genes and pathways in hepatocellular carcinoma. Nat Genet. 2012;44(6):694-8.

77. Wang K, Kan J, Yuen ST, Shi ST, Chu KM, Law S, et al. Exome sequencing identifies frequent mutation of ARID1A in molecular subtypes of gastric cancer. Nat Genet. 2011;43(12):1219-23.

78. Sausen M, Leary RJ, Jones S, Wu J, Reynolds CP, Liu X, et al. Integrated genomic analyses identify ARID1A and ARID1B alterations in the childhood cancer neuroblastoma. Nat Genet. 2013;45(1):12-7.

79. Takao C, Morikawa A, Ohkubo H, Kito Y, Saigo C, Sakuratani T, et al. Downregulation of ARID1A, a component of the SWI/ SNF chromatin remodeling complex, in breast cancer. J Cancer. 2017;8(1):1-8.

80. Cho HD, Lee JE, Jung HY, Oh MH, Lee JH, Jang SH, et al. Loss of tumor suppressor ARID1A protein expression correlates with poor prognosis in patients with primary breast cancer. J Breast Cancer. 2015;18(4):339-46.

81. Yang L, Wei S, Zhao R, Wu Y, Qiu H, Xiong H. Loss of ARID1A expression predicts poor survival prognosis in gastric cancer: a systematic meta-analysis from 14 studies. Sci Rep. 2016;29(6):28919.

82. Wiegand KC, Shah SP, Al-Agha OM, Zhao Y, Tse K, Zeng T, et al. ARID1A mutations in endometriosis-associated ovarian carcinomas. N Engl J Med. 2010;363(16):1532-43.

83. Kubiak M, Lewandowska MA. Can chromatin conformation technologies bring light into human molecular pathology? Acta Biochim Pol. 2015;62(3):483-9.

84. Jia R, Chai P, Zhang H, Fan X. Novel insights into chromosomal conformations in cancer. Mol Cancer. 2017;16(1):173.

85. Herold M, Bartkuhn M, Renkawitz R. CTCF: insights into insulator function during development. Development. 2012;139(6):1045-57.
86. Oh S, Oh C, Yoo KH. Functional roles of CTCF in breast cancer. BMB Rep. 2017;50(9):445-53.

87. Wang XQD, Dostie J. Chromosome folding and its regulation in health and disease. Curr Opin Genet Dev. 2017;43:23-30.

88. Liu J, Ding Z, Li G, Tang L, Xu Y, Luo H, et al. Identification and validation of colorectal neoplasia-specific methylation biomarkers based on CTCF-binding sites. Oncotarget. 2017;8(69):114183-94.

89. Green AR, Krivinskas S, Young P, Rakha EA, Paish EC, Powe DG, et al. Loss of expression of chromosome 16q genes DPEP1 and CTCF in lobular carcinoma in situ of the breast. Breast Cancer Res Treat. 2009;113(1):59-66.

90. Lee RC, Feinbaum RL, Ambros V. The C. elegans heterochronic gene lin-4 encodes small RNAs with antisense complementarity to lin-14. Cell. 1993;75(5):843-54.

91. Calin GA, Dumitru CD, Shimizu M, Bichi R, Zupo S, Noch E, et al. Frequent deletions and down-regulation of micro- RNA genes miR15 and miR16 at 13q14 in chronic lymphocytic leukemia. Proc Natl Acad Sci USA. 2002;99(24):15524-9.

92. Cimmino A, Calin GA, Fabbri M, Iorio MV, Ferracin M, Shimizu $\mathrm{M}$, et al. miR-15 and miR-16 induce apoptosis by targeting BCL2. Proc Natl Acad Sci USA. 2005;102(39):13944-9.

93. Van Dyke DL, Shanafelt TD, Call TG, Zent CS, Smoley SA, Rabe KG, et al. A comprehensive evaluation of the prognostic significance of $13 \mathrm{q}$ deletions in patients with B-chronic lymphocytic leukaemia. Br J Haematol. 2010;148(4):544-50.

94. Li J, Smyth P, Flavin R, Cahill S, Denning K, Aherne S, et al. Comparison of miRNA expression patterns using total RNA extracted from matched samples of formalin-fixed paraffinembedded (FFPE) cells and snap frozen cells. BMC Biotechnol. 2007;29(7):36.

95. Czubak K, Lewandowska MA, Klonowska K, Roszkowski K, Kowalewski J, Figlerowicz M, et al. High copy number variation of cancer-related microRNA genes and frequent amplification of DICER1 and DROSHA in lung cancer. Oncotarget. 2015;6(27):23399-416.

96. Li N, Kaur S, Greshock J, Lassus H, Zhong X, Wang Y, et al. A combined array-based comparative genomic hybridization and functional library screening approach identifies mir-30d as an oncomir in cancer. Cancer Res. 2012;72(1):154-64.

97. Manceau G, Imbeaud S, Thiébaut R, Liébaert F, Fontaine K, Rousseau F, et al. Hsa-miR-31-3p expression is linked to progression-free survival in patients with KRAS wild-type metastatic colorectal cancer treated with anti-EGFR therapy. Clin Cancer Res. 2014;20(12):3338-47.

98. Gilad S, Lithwick-Yanai G, Barshack I, Benjamin S, Krivitsky I, Edmonston TB, et al. Classification of the four main types of lung cancer using a microRNA-based diagnostic assay. J Mol Diagn. 2012;14(5):510-7.

99. Barh D, Carpi A, Verma M, Gunduz M, editors. Cancer biomarkers: minimal and noninvasive early diagnosis and prognosis. Boca Raton: CRC; 2017.

100. Roush S, Slack FJ. The let-7 family of microRNAs. Trends Cell Biol. 2008;18(10):505-16.

101. Boyerinas B, Park S-M, Hau A, Murmann AE, Peter ME. The role of let-7 in cell differentiation and cancer. Endocr Relat Cancer. 2010;17(1):F19-36.

102. Buscaglia LEB, Li Y. Apoptosis and the target genes of microRNA-21. Chin J Cancer. 2011;30(6):371-80.

103. Cmarik JL, Min H, Hegamyer G, Zhan S, Kulesz-Martin M, Yoshinaga H, et al. Differentially expressed protein Pdcd4 inhibits tumor promoter-induced neoplastic transformation. Proc Natl Acad Sci USA. 1999;96(24):14037-42. 
104. Jansen AP, Camalier CE, Colburn NH. Epidermal expression of the translation inhibitor programmed cell death 4 suppresses tumorigenesis. Cancer Res. 2005;65(14):6034-41.

105. Leupold JH, Yang H-S, Colburn NH, Asangani I, Post S, Allgayer $\mathrm{H}$. Tumor suppressor Pdcd4 inhibits invasion/intravasation and regulates urokinase receptor (u-PAR) gene expression via Sp-transcription factors. Oncogene. 2007;26(31):4550-62.

106. Larrea E, Sole C, Manterola L, Goicoechea I, Armesto M, Arestin M, et al. New concepts in cancer biomarkers: circulating miRNAs in liquid biopsies. Int J Mol Sci. 2016. https://doi. org/10.3390/ijms17050627.

107. Resnick KE, Alder H, Hagan JP, Richardson DL, Croce CM, Cohn DE. The detection of differentially expressed microRNAs from the serum of ovarian cancer patients using a novel real-time PCR platform. Gynecol Oncol. 2009;112(1):55-9.

108. Ryu JK, Matthaei H, Dal Molin M, Hong SM, Canto MI, Schulick RD, et al. Elevated microRNA miR-21 levels in pancreatic cyst fluid are predictive of mucinous precursor lesions of ductal adenocarcinoma. Pancreatology. 2011;11(3):343-50.

109. Zeng Z, Wang J, Zhao L, Hu P, Zhang H, Tang X, et al. Potential role of microRNA-21 in the diagnosis of gastric cancer: a metaanalysis. PloS One. 2013;8(9):e73278.

110. Shiotani A, Murao T, Kimura Y, Matsumoto H, Kamada T, Kusunoki $\mathrm{H}$, et al. Identification of serum miRNAs as novel noninvasive biomarkers for detection of high risk for early gastric cancer. Br J Cancer. 2013;109(9):2323-30.

111. Song L, Jia J, Peng X, Xiao W, Li Y. The performance of the SEPT9 gene methylation assay and a comparison with other CRC screening tests: a meta-analysis. Sci Rep. 2017;7(1):3032.

112. American Cancer Society Guideline for Colorectal Cancer Screening. 2018. https://www.cancer.org/cancer/colon-recta 1-cancer/detection-diagnosis-staging/acs-recommendations.html. Accessed 1 July 2018.

113. Nian J, Sun X, Ming S, Yan C, Ma Y, Feng Y, et al. Diagnostic accuracy of methylated SEPT9 for blood-based colorectal cancer detection: a systematic review and meta-analysis. Clin Transl Gastroenterol. 2017;8(1):e216.

114. Thon N, Kreth S, Kreth FW. Personalized treatment strategies in glioblastoma: MGMT promoter methylation status. Onco Targets Ther. 2013;27(6):1363-72.

115. Fiorentino A, Balducci M, De Bonis P, Chiesa S, De Filippo L, Mangiola A, et al. Can elderly patients with newly diagnosed glioblastoma be enrolled in radiochemotherapy trials? Am J Clin Oncol. 2015;38(1):23-7.

116. Wang Z, Jiang W, Wang Y, Guo Y, Cong Z, Du F, et al. MGMT promoter methylation in serum and cerebrospinal fluid as a tumor-specific biomarker of glioma. Biomed Rep. 2015;3(4):543-8.

117. Catuogno S, Esposito CL, Condorelli G, de Franciscis V. Nucleic acids delivering nucleic acids. Adv Drug Deliv Rev. Epub 2018 Apr 6. https://doi.org/10.1016/j.addr.2018.04.006.

118. Selaru FM, Olaru AV, Kan T, David S, Cheng Y, Mori Y, et al. MicroRNA-21 is overexpressed in human cholangiocarcinoma and regulates programmed cell death 4 and tissue inhibitor of metalloproteinase 3. Hepatology. 2009;49(5):1595-601.

119. Verma M, Kumar V. Chapter 21-Epigenetic drugs for cancer and precision medicine. In: Moskalev A, Vaiserman AM, editors. Epigenetics of aging and longevity. Boston: Academic; 2018. p. 439-51.

120. Jones PA, Issa JP, Baylin S. Targeting the cancer epigenome for therapy. Nat Rev Genet. 2016;17(10):630-41.
121. Biswas S, Rao CM. Epigenetic tools (the writers, the readers and the erasers) and their implications in cancer therapy. Eur J Pharmacol. 2018;15(837):8-24.

122. Eckschlager T, Plch J, Stiborova M, Hrabeta J. Histone deacetylase inhibitors as anticancer drugs. Int $\mathrm{J}$ Mol Sci. 2017;18(7):1414.

123. Valdespino V, Valdespino PM. Potential of epigenetic therapies in the management of solid tumors. Cancer Manag Res. 2015;7:241-51.

124. van den Bent MJ, Erdem-Eraslan L, Idbaih A, de Rooi J, Eilers PH, Spliet WG, et al. MGMT-STP27 methylation status as predictive marker for response to $\mathrm{PCV}$ in anaplastic oligodendrogliomas and oligoastrocytomas. A report from EORTC study 26951. Clin Cancer Res. 2013;19(19):5513-22.

125. Mastoraki S, Strati A, Tzanikou E, Chimonidou M, Politaki E, Voutsina A, et al. ESR1 methylation: a liquid biopsy-based epigenetic assay for the follow-up of patients with metastatic breast cancer receiving endocrine treatment. Clin Cancer Res. 2018;24(6):1500-10.

126. Vedeld HM, Nesbakken A, Lothe RA, Lind GE. Re-assessing ZNF331 as a DNA methylation biomarker for colorectal cancer. Clin Epigenetics. 2018;10:70.

127. Misawa K, Misawa Y, Imai A, Mochizuki D, Endo S, Mima M, et al. Epigenetic modification of SALL1 as a novel biomarker for the prognosis of early stage head and neck cancer. J Cancer. 2018;9(6):941-9.

128. Rahier JF, Druez A, Faugeras L, Martinet JP, Gehenot M, Josseaux E, et al. Circulating nucleosomes as new blood-based biomarkers for detection of colorectal cancer. Clin Epigenetics. 2017;9:53.

129. Liu H, Li Y, Li J, Liu Y, Cui B. H3K4me3 and Wdr82 are associated with tumor progression and a favorable prognosis in human colorectal cancer. Oncol Lett. 2018;16(2):2125-34.

130. Bell EH, Chakraborty AR, Mo X, Liu Z, Shilo K, Kirste S, et al. SMARCA4/BRG1 is a novel prognostic biomarker predictive of cisplatin-based chemotherapy outcomes in resected non-small cell lung cancer. Clin Cancer Res. 2016;22(10):2396-404.

131. Huang Z, Huang D, Ni S, Peng Z, Sheng W, Du X. Plasma microRNAs are promising novel biomarkers for early detection of colorectal cancer. Int J Cancer. 2010;127(1):118-26.

132. Krawczyk P, Powrózek T, Olesiński T, Dmitruk A, Dziwota J, Kowalski D, et al. Evaluation of miR-506 and miR-4316 expression in early and non-invasive diagnosis of colorectal cancer. Int J Colorectal Dis. 2017;32(7):1057-60.

133. Leng Q, Lin Y, Jiang F, Lee CJ, Zhan M, Fang H, et al. A plasma miRNA signature for lung cancer early detection. Oncotarget. 2017;8(67):111902-11.

134. Fogli S, Polini B, Carpi S, Pardini B, Naccarati A, Dubbini N, et al. Identification of plasma microRNAs as new potential biomarkers with high diagnostic power in human cutaneous melanoma. Tumour Biol. 2017;39(5):1010428317701646.

135. Lin HM, Castillo L, Mahon KL, Chiam K, Lee BY, Nguyen Q, et al. Circulating microRNAs are associated with docetaxel chemotherapy outcome in castration-resistant prostate cancer. $\mathrm{Br}$ J Cancer. 2014;110(10):2462-71.

136. Integragen. miRpredX 31-3p. http://www.integragen.com/mirpr edx-31-3p-2. Accessed 1 July 2018.

137. Microrna biomarker for the diagnosis of gastric cancer [patent application EP3177739A1]. https://patents.google.com/patent/ EP3177739A1/en. Accessed 1 July 2018. 